\title{
FAKTOR-FAKTOR YANG MEMPENGARUHI KETIDAK PATUHAN PASIEN DIABETES MELLITUS DALAM KONTROL ULANG DI RUANGAN PENYAKIT DALAM RUMAH SAKIT SANTA ELISAEBTH MEDAN TAHUN 2018
}

\author{
Connie Melva Sianipar \\ Dosen D III Keperawatan STIKes Santa Elisabeth Medan, Jalan Bunga Terompet No. 118 Medan \\ E-mail: cinniems@yahoo.com
}

\begin{abstract}
ABSTRAK
Penyakit Diabetes Mellitus (DM) adalah penyakit seumur hidup dan tidak dapat disembuhkan, akan tetapi kadar glukosa darah dapat dikendalikan sedemikian rupa. Salah satu cara untuk mengatasi akibat lebih lanjut dari diabetes mellitus adalah dengan penerapan kontrol diabetes mellitus. Namun sampai saat ini banyak ditemukan penderita diabetes mellitus yang tidak patuh dalam pelaksanaan kontrol ulang. Penelitian ini bertujuan untuk mengidentifikasi faktor-faktor yang mempengaruhi ketidakpatuhan pasien diabetes mellitus dalam kontrol ulang di ruangan penyakit dalam Rumah Sakit Santa Elisabeth Medan 2018. Jenis penelitian yang digunakan adalah penelitian deskriptif dengan jenis pendekatan cross sectional. Populasi pada penelitian ini adalah pasien DM yang di rawat di Rumah Sakit Santa Elisabeth Medan yang berjumlah 243 orang. Teknik pengambilan sampel menggunakan purposive sampling, peneliti menggunakan $15 \%$ dari jumlah populasi. Sehingga pada penelitian ini dengan menggunakan sampel 36 orang. Hasil penelitian ini adalah faktor ketidakpatuhan yang paling besar adalah pemahaman instruksi 21 responden dengan persentase 58.3\%, kualitas insteraksi 20 responden 55.6\%, dan keluarga 14 responden 38.9\%. Disimpulkan bahwa ketaatan terhadap pendidikan kesehatan mendapat nilai tertinggi dan dukungan keluarga dalam nilai terendah, ini adalah situasi kritis dalam pengendalian ulang di Rumah Sakit Dalam untuk rumah sakit. Saran kepada manajemen rumah sakit dan para-medis tersebut harus memperbaiki interaksi mereka dalam memberikan instruksi kepada penderita diabetes mellitus.
\end{abstract}

Kata Kunci: Faktor ketidakpatuhan, Diabetes Mellitus

\section{ABSTRACT}

Diabetes mellitus is acknowledged a hereditary disease and sometimes by other factors may sometimes occur on all aged but mostly noted to those over 45 years old. Patient DM is required highly to make routinely control over blood sugar, they must obey the schedule. It is surely disobedience lead them unable to heal away from the disease. This study aimed to determine the factors disobedience influencing those patient with diabetes mellitus in re-controlling. at 2018. Design used in this research is well known in descriptive with cross-sectional approach, with the sample 36 respondents. The method in taking the sample is purposive sampling. The instrument used is questionnaire. The results noted their obedience for instruction is about 58,3\%, quality of interaction is 55,6\%, and on their family 38,9\%. It is concluded that obedience to instruction got highest rate and family supported in lowest rate, this is critical situation in re-controlling in Ruangan Penyakit Dalam for the hospital. It is suggested to the management of hospital and those para-medic should improve their interaction in giving instruction to the patient with diabetes mellitus.

Keywords: Disobedience Factor, Diabetes Mellitus

\section{PENDAHULUAN}

Penyakit Diabetes Mellitus (DM) adalah penyakit seumur hidup dan tidak dapat disembuhkan, akan tetapi kadar glukosa darah dapat dikendalikan sedemikian rupa (Tandra, 2007). Diabetes mellitus ditandai oleh kenaikan kadar glukosa dalam darah (Smeltzer, 2002).

Menurut Baradero

(2009), penyebabnya adalah akibat kurangnya 
sekresi insulin atau ada insulin yang cukup, tetapi tidak efektif.

Diabetes mellitus terdiri dari 2 type yaitu diabetes mellitus tipe I dan diabetes mellitus tipe II. Tipe I terjadi sejak balita atau remaja, kemudian diketahui bahwa siapapun dari segala usia juga dapat menderita tipe I ini meskipun mayoritas kasus yang ada adalah pada usia 30 tahun kebawah. Tipe II dipengaruhi oleh gen / keturunan (Arisman, 2010).

Penderita diabetes dituntut untuk melaksanakan berbagai pengaturan yang berkaitan dengan pengontrolan glukosa darah agar metabolismeya dapat terkendali dengan baik. Hal yang dirasakan berat oleh adanya penanganan dan tuntutan yang lebih tinggi untuk melakukan seperti pemeriksaan kadar gula darah (Safitri, 2013) Pasien mungkin tidak mematuhi tujuan atau mungkin melupakan instruksi yang diberikan seperti pada pasien diabetes mellitus yaitu rutin untuk mengontrol kadar gula darahnya.

WHO (2013) Indonesia tergolong pada urutan ke 4 penderita DM dengan jumlah pasien terbesar dunia setelah India, Cina, dan Amerika Serikat dengan jumlah sekitar 17 juta orang. Penderita diabetes mellitus didunia meningkat hampir setiap tahunnya, seperti tahun 1994 sebesar 110,4 juta menjadi 150 juta penderita, tahun 2010 sebesar 279,3 juta dan pada tahun 2020 diperkirakan sebesar 300 juta. Di Indonesia terdapat penderita DM sebesar 5,7\% yang terdiri dari $1,5 \%$ atau sebesar $2,6 \%$ dari total penderita mengetahui bahwa dirinya DM dan $4,2 \%$ atau $7,4 \%$ tidak mengetahui dirinya DM, dimana prevalensi DM meningkat pada usia $\geq 35$ tahun dan menurun setelah usia $>74$ tahun

Kepatuhan seseorang dalam menjalani pengobatan sering kali terganggu dengan beberapa pantangan dalam pengobatan tersebut. Pengendalian diri dan dari lingkungan luar sangat berpengaruh erat dengan kepatuhan. Tingkat kepatuhan pada penderita DM dalam kontrol ulang di rumah sakit terdapat $43,5 \%$ yang patuh dan $56,5 \%$ yang tidak patuh. (Safitri, 2013). Kepatuhan merupakan prosedur serta pengaruh sosial yang memberi perhatian untuk memberitahu atau memerintah orang untuk melakukan sesuatu daripada meminta untuk melakukannya, dimana bahwa orang mematuhi perintah dari orang yang mempunyai kekuasaan bukanlah yang mengherankan (Niven, 2012).

Berdasarkan survei awal yang diperoleh dari rumah sakit santa Elisabeth Medan jumlah pasien DM yang dirawat pada tahun 2015. Di Poli Klink Penyakit Dalam sekitar 144 orang yang menjalani kontrol ulang selama tahun 2016, dan diantaranya pasien berjenis kelamin perempuan 81 orang dan 63 berjenis kelamin laki-laki.

Kondisi penderita diabetes tergantung pada individu masing-masing terutama dari segi kepatuhan. Banyak penderita diabetes yang memulai usaha tersebut secara antusias, namun pada tahun-tahun berikutnya antusiasme tersebut menjadi luntur, dan mereka mungkin tidak menyadari bahwa kendali mereka sudah tidak sebaik sebelumnya (Safitri, 2013) Salah satu cara untuk mengatasi akibat lebih lanjut dari diabetes mellitus adalah dengan penerapan kontrol diabetes mellitus. Namun sampai saat ini banyak ditemukan penderita diabetes mellitus yang tidak patuh dalam pelaksanaan kontrol ulang.

\section{METODE}

Rancangan penelitian yang digunakan oleh peneliti adalah penelitian deskriptif dengan jenis pendekatan cross sectional, adalah jenis penelitian yang menekankan pada waktu pengukuran dimana hanya satu kali pada satu saat, jadi tidak ada tindak lanjut (Nursalam, 2013). Populasi pada penelitian ini adalah pasien DM yang di rawat di Rumah Sakit Santa Elisabeth Medan yang berjumlah 243 orang. Teknik pengambilan sampel pada penelitian ini adalah purposive sampling.

Pengambilan sampel menggunakan rumus menurut Arikunto (2006), peneliti menggunakan $15 \%$ dari jumlah poulasi. Sehingga pada penelitian ini dengan menggunakan sampel 36 orang. Kriteria inklusi dalam penelitian ini yaitu:

1. Pasien yang berusia $>45$ tahun,

2. Pasien yang memiliki riwayat DM antara lebih dari 3tahun,

3. Pasien yang tidak ada komplikasi.

Instrumen yang digunakan adalah kuesioner yang dibuat sendiri oleh peneliti. Kuesioner berisikan mengenai 
ketidakpatuhan pasien DM dalam melakukan kontrol ulang yang terdiri dari 45 pernyataan. Bagian pertama adalah kuesioner tentang pemahaman instruksi pasien terhadap ketidakpatuhan pasien DM dalam kontrol ulang yang berisi 15 pernyataan, bagian kedua adalah kuesioner tentang kualitas interaksi terhadap ktidakpatuhan pasien DM dalam kontrol ulang yang berisi 15 pernyataan, serta bagian ketiga adalah kuesioner dukungan keluarga yang terdiri 15 pernyataan. Nilai tertinggi yang diperoleh adalah 45 dan terendah adalah 0 .

Mengetahui pemahaman instruksi, kualitas interaksi, dan dukungan keluarga pada pasien Diabetes Mellitus dianalisa dengan menggunakan skala nominal yaitu dengan mengkategorikan ya atau tidak. Berdasarkan rumus statistika menurut Sudjana (2001):

$$
\mathrm{P}=\frac{\text { rentang }}{\text { banyak kelas }}
$$

Dimana $\mathrm{P}$ merupakan panjang kelas dengan rentang sebesar 45 (selisih nilai tertinggi dan nilai terendah) dan banyak kelas 2 ( ya dan tidak) maka didapatkan panjang kelas sebesar $45 / 2=22,5$ atau dibulatkan 23, sehingga dikategorikan atas interval: patuh (0-23) dan tidak patuh (2445). Faktor yang mempengaruhi ketidakpatuhan untuk indikator pemahaman instruksi terdiri dari 15 pernyataan dan banyak kelas 2 maka didapatkan panjang kelas 8 sehingga faktor yang mempengaruhi ketidakpatuhan dari pemahaman instruksi dikategorikan patuh: (0-8) dan tidak patuh (9-15). Faktor yang mempengaruhi ketidakpatuhan untuk indikator kualitas interaksi terdiri dari 15 pernyataan dan banyak kelas 2 maka didapatkan panjang kelas 8 sehingga faktor yang mempengaruhi ketidakpatuhan dari kualitas interaksi dikategorikan patuh: (0-8) dan tidak patuh (9-15). Faktor yang mempengaruhi ketidakpatuhan untuk indikator keluarga terdiri dari 15 pernyataan dan banyak kelas 2 maka didapatkan panjang kelas 8 sehingga faktor yang mempengaruhi ketidakpatuhan dari keluarga dikategorikan patuh: (0-8) dan tidak patuh (9-15)
Penelitian ini telah dilakukan di ruangan penyakit dalam Rumah Sakit Santa Elisabeth Medan. Penelitian ini dilakukan mulai pada bulan Maret 2017

Mengetahui kevaliditasan penelitian ini maka digunakan uji pearson product moment dengan taraf signifikansi $0,5 \%$. Uji validitas didapatkan dari kuesioner pada 30 responden. Uji validitas telah dilakukan di Poli Praktek Penyakit Dalam Rumah Sakit Santa Elisabeth Medan. Dari hasil analisis, ditemukan dari 45 pertanyaan kuesioner faktor ketidakpatuhan, tidak terdapat nilai $r$ hitung lebih kecil dari nilai $r$ tabel, dimana nilai $\mathrm{r}$ tabel pada tingkat signifikansi 5\% adalah 0,374 sehingga semua pertanyaan tersebut dinyatakan valid dan dapat digunakan saat penelitian.

Dari hasil uji yang dilakukan pada variable faktor ketidakpatuhan diperoleh nilai $\alpha=0,944$ sehingga instrument penelitian tersebut dikatakan reliable dan layak digunakan. Data dianalisa menggunakan alat bantu program statistik komputer yaitu dengan analisis univariat yang bertujuan untuk mendeskripsikan karakteristik setiap variable penelitian. Analisis univariat pada penelitian ini adalah distribusi frekuensi responden berdasarkan umur, jenis kelamin, dan hasil dari masingmasing faktor ketidakpatuhan

\section{HASIL}

Distribusi dan persentase menurut tingkat umur dari 36 responden, pada kelompok umur 55-75 tahun yaitu sebanyak 19 responden (52,8\%). Jenis kelamin didapatkan responden yang terbanyak didapatkan pada kelompok jenis kelamin laki-laki yaitu 16 responden $(44,4 \%)$ dan jenis kelamin perempuan yaitu 20 responden $(55,6 \%)$. Pendidikan didapatkan responden yang terbanyak didapatkan pada pendidikan SMA yaitu sebanyak 13 responden $(36,1 \%)$. Suku didapatkan responden yang terbanyak didapatkan pada kelompok suku batak toba yaitu 22 responden $(61,1 \%)$.

Tabel 1. Distribusi frekuensi dan persentase faktor-faktor ketidakpatuhan pasien Diabetes Mellitus dalam kontrol ulang di ruangan penyakit dalam di Rumah Sakit Santa Elisabeth Medan 2018 


\begin{tabular}{lcccc}
\hline faktor ketidakpatuhan & frekuensi patuh & frekuensi tidak patuh & Persentase & Persentase \\
\hline Pemahaman instruksi & 15 & 21 & $41,7 \%$ & $58.3 \%$ \\
Kualitas interaksi & 16 & 20 & $44,4 \%$ & $55.6 \%$ \\
Keluarga & 22 & 14 & $61,1 \%$ & $38.9 \%$ \\
\hline
\end{tabular}

Berdasarkan tabel diatas distribusi frekuensi dan persentase pendokumentasian pengumpulan data pasien diabetes mellitus dalam kontrol ulang di Ruangan Penyakit Dalam Rumah Sakit Santa Elisabeth Medan dapat dilihat bahwa faktor ketidakpatuhan yang paling besar adalah pemahaman instruksi 21 responden dengan persentase $58.3 \%$, kualitas insteraksi 20 responden $55.6 \%$, dan keluarga 14 responden $38.9 \%$.

\section{PEMBAHASAN}

\section{Faktor ketidakpatuhan berdasarkan pemahaman instruksi}

Berdasarkan hasil penelitian di Ruangan Penyakit Dalam Rumah Sakit Santa Elisabeth Medan didapatkan bahwa 21 orang penderita $\mathrm{DM}(58,3 \%)$ memiliki pemahaman instruksi yang kurang sehingga mengakibatkan pasien tidak patuhan dalam kontrol ulang

Penelitian ini sejalan dengan penelitian Liliweri dalam penelitian Nurul Afifah (2014), yang mengatakan bahwa kepatuhan berobat dipengaruhi oleh instruksi yang diberikan oleh tenaga kesehatan sehingga instruksi tersebut harus dipahami oleh penderita dan tidak menimbulkan persepsi yang salah.

Didukung oleh teori Niven (2002) tentang faktor-faktor yang mempengaruhi ketidakpatuhan yang mengatakan bahwa tak seorang pun dapat mematuhi instruksi jika ia salah paham tentang instruksi. Hal ini disebabkan oleh kegagalan professional kesehatan dalam memberikan instruksi, penggunaan istiah-istilah medis dan memberikan banyak instruksi yang harus diingat oleh pasien.

Peneliti mendapatkan bahwa semakin rendah pemahaman instruksi seseorang terhadap instruksi yang diberikan maka semakin tinggi pula ketidakpatuhan pasien dalam kontrol ulang. Dari hasil pertanyaan yang diajukan peneliti, responden mengatakan instruksi yang diberikan oleh tenaga kesehatan terlalu banyak dan tenaga kesehatan masih menggunakan kata-kata medis, sehingga mempengaruhi sikap dan kesadaran pasien untuk rutin kontrol ulang.

\section{Faktor ketidakpatuhan berdasarkan kualitas interaksi}

Hasil penelitian di Ruangan Penyakit Dalam Rumah Sakit Santa Elisabeth Medan didapatkan bahwa 20 orang penderita DM $(55,6 \%)$ menunjukkan kualitas interaksi yang rendah dengan tenaga kesehatan sehingga mengakibatkan pasien DM tidak patuh untuk kontrol ulang

Hal ini sejalan dengan pendapat Dewi C dalam penelitian Nurul Afifah (2014), yang mengatakan bahwa kepatuhan berobat dipengaruhi oleh kualitas interaksi antara tenaga kesehatan dengan pasien. Keluhan yang spesifik yang dirasakan oleh pasien adalah kurangnya empati dan kurangnya minat yang diperlihatkan oleh dokter (Niven, 2002).

Kualitas interaksi yang rendah akan membuat ketidakpatuhan pasien dalam kontrol ulang akan semakin meningkat. Kualitas interaksi tenaga kesehatan dengan pasien diabetes mellitus yang baik akan memotivasi pasien untuk rutin dan teratur menjalani kontrol ulang.

\section{Faktor ketidakpatuhan berdasarkan dukungan keluarga}

Penelitian di Ruangan Penyakit Dalam Rumah Sakit Santa Elisabeth Medan didapatkan bahwa 13 orang penderita DM $(38,9 \%)$ mengalami dukungan keluarga yang tergolong rendah sehingga mengakibatkan pasien DM tidak patuh untuk kontrol ulang.

Banu (2011), yang mengatakan bahwa kurangnya dukungan keluarga disebabkan sebagian besar keluarga menganggap bahwa pasien telah memahami tentang penyakitnya . Dukungan keluarga yang tinggi akan menyebabkan pasien merasa senang dan tentram karena dukugan tersebut akan menimbulkan kepercayaan diri untuk menghadapi penyakit.

Penelitian diatas didukung oleh teori Niven (2002) tentang faktor-faktor ketidakpatuhan yang mengatakan bahwa keluarga dapat menjadi faktor yang sangat berpengaruh dalam menentukan nilai kesehtan individu serta menentukan 
program pengobatan yang dapat mereka terima. Keluarga dapat menasehati dan mengawasi pasien agar rutin berobat dan minum obatnya secara teratur.

Peneliti dapat menyimpulkan bahwa dukungan keluarga yang didapatkan oleh pasien masih tergolong rendah. Itu dapat dibuktikan dengan pasien yang masih mengikuti program kontrol ulang jarang ditemani oleh keluarga dan juga jarang diingingatkan keluarga untuk mengkonsumsi obat.

\section{KESIMPULAN}

Berdasarkan hasil penelitian mengenai faktor-faktor yang mempengaruhi ketidakpatuhan pasien DM dalam kontrol ulang di Ruangan Penyakit Dalam Rumah Sakit Santa Elisabeth Medan, diperoleh simpulan sebagai berikut:

1. Distribusi frekuensi pemahaman pasien tentang instruksi yang diberikan pada pasien diabetes mellitus di ruangan penyakit dalam Rumah Sakit Santa Elisabeth Medan diperoleh sebanyak $(58,3 \%)$.

2. Distribusi frekuensi kualitas insteraksi tenaga kepada pasien diabetes mellitus di ruangan penyakit dalam rumah sakit santa Elisabeth medan diperoleh sebanyak $(55,6 \%)$.

3. Distribusi frekuensi dukungan keluarga bagi pasien diabetes mellitus di ruangan penyakit dalam rumah sakit santa Elisabeth Medan diperoleh sebanyak $(38,9 \%)$.

\section{SARAN}

Adapun saran dari peneliti dalam penelitian ini adalah pemberian informasi oleh perawat-perawat Ruangan Penyakit Dalam Rumah Sakit Santa Elisaebth Medan kepada pasien DM, pemasangan poster di dinding tentang informasi penyakit DM dan Diit Gizi penderita DM, memberikan penyuluhan kepada kepada keluarga pasien agar dapat merawat pasien di rumah setelah pengobatan dari rumah sakit, pemberian pelatihan tentang DM kepada perawat ruangan Penyakit Dalam Rumah Sakit Santa Elisabeth Medan serta memperbanyak interaksi dengan memberikan dukungan dan motivasi kepada pasien yang dirawat di Ruangan Penyakit Dalam Rumah Sakit Santa Elisabeth Medan.

\section{DAFTAR PUSTAKA}

Arikunto,S. (2010). Prosedur Penelitian Suatu Pendekatan Praktek. Jakarta: Rineka Cipta.

Arisman. (2010). Obesitas, Diabetes Mellitus dan Dislipidemia. Jakarta: EGC.

Aspuah, S. (2013). Kumpulan Kuesioner Dan Instrumen Penelitian Kesehatan. Yogyakarta: Nuha Medika.

Atkinson, dkk. (1983). Pengantar Psikologi. Jakarta: Erlangga.

Baradero, M. (2009). Seri Asuhan Keperawatan Klien Gangguan Endokrin. Jakarta: EGC.

Corwin, E. J. (2009). Patofisiologi. Jakarta: EGC.

Dewi, N. (2012). Hubungan Dukungan Pasangan Dan Health Locus Of Control Dengan Kepatuhan Dalam Menjalani Proses Pengobatan Pada Penderita Diabetes Mellitus Tipe 2. Journal Ubaya. (1): 56-65.

Fransiska, K. (2012). Awas Pankreas Rusak Penyebab Diabetes. Jakarta: Cerdas Sehat.

Garnadi, Y. (2012). Solusi Sehat Dari Dokter Hidup Nyaman Dengan Diabetes Mellitus . Jakarta: Agro Media Pustaka.

Niven, N. (2002). Psikologi Kesehatan Pengantar Untuk Perawat \& Profesional Kesehatan Lain. Jakarta: EGC.

Notoatmodjo, S. (2010). Metodologi Penelitian Kesehatan. Jakarta: Rineka Cipta.

Nursalam. (2013). Metodologi Penelitian Ilmu Keperawatan Edisi 3. Jakarta: Penerbit Salemba Medika.

Price \& Wilson. (2006). Patofisiologi; Konsep Klinis Proses-proses Penyakit Edisi 6 Vol 2. Jakarta: EGC.

Rendy \& Margareth. (2012). Asuhan Keperawatan Medikal Bedah Penyakit Dalam. Yogyakarta: Nuha Medika.

Rosanna. (2012). Kepatuhan Kontrol Dengan Tingkat Kadar Gula Darah Pasien Diabetes Mellitus Di Rumah Sakit Baptis Kediri. Portal Garuda. 
Safitri, I. (2013). Kepatuhan Penderita Diabetes Mellitus Tipe II Ditinjau Dari Locus Of Control. Ejournal UMM (1):1583-1686.

Saryono. (2011). Metodologi Penelitian Kesehatan Penuntun Praktis Bagi Pemula. Yogyakarta. Buku Kesehatan.

Smeltzer \& Bare. (2002). Buku Ajar Keperawatan Medikal Bedah Edisi 8 vol 2. Jakarta: EGC.

Sugiono. (2010). Metode Penelitian Kuantitatif, Kualitatif dan $R \& D$. Bandung: Alfa Beta

Sujarweni, W. (2014). Metodologi Penelitian Keperawatan. Yogyakarta: Penerbit Gava Media
Sustrani, dkk. (2010). Diabetes. Jakarta: PT Gramedia Pustaka Utama.

Sutanto, T. (2013). Diabetes Deteksi, Pencegahan, Pengobatan. Yogyakarta: Buku Pintar

Tandra, H. (2007). Segala Sesuatu Yang Harus Anda Ketahui Tentang Diabetes. Jakarta: Gramedia Pustaka Utama

Tandra, Hans. (2013). Life Heaalthy With Diabetes. Yogyakarta: Rapha Publishing.

Tjokroprawiro, A. (1997). Hidup Sehat dan Bahagia Bersama Diabetes Mellitus. Jakarta: Gramedia Pustaka Utama.

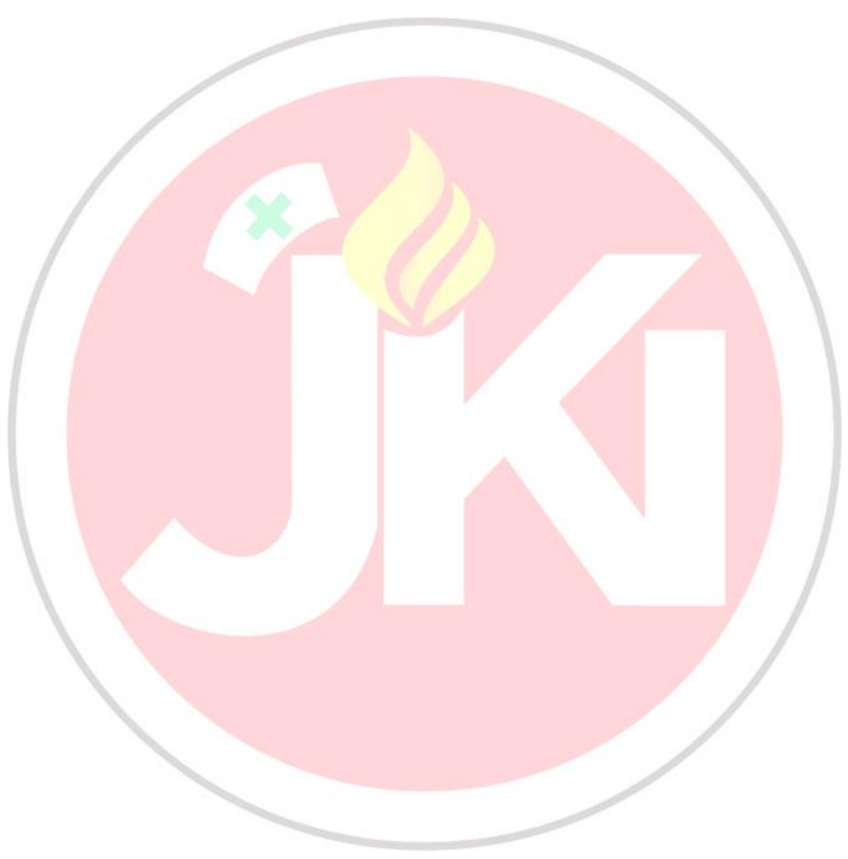

